\title{
Correlation between Apolipoprotein B/Apolipoprotein A-I Ratio with Atherogenic Index of Plasma among Acute Myocardial Infarction Patients
}

\author{
Winardi Emmanuel Setiawan, Anggoro Budi Hartopo ${ }^{2, *}$, Royhan Rozqie ${ }^{2}$ \\ ${ }^{1}$ Undergraduate Study Program on Medicine, Faculty of Medicine, Universitas Gadjah Mada, Jl. Farmako Sekip Utara, Yogyakarta, Indonesia \\ ${ }^{2}$ Department of Cardiology and Vascular Medicine, Faculty of Medicine, Universitas Gadjah Mada - Dr. Sardjito Hospital, Jl. Farmako Sekip Utara, \\ Yogyakarta, Indonesia \\ *Corresponding author. E-mail: a_bhartopo@ugm.ac.id
}

Received date: Oct 12, 2017; Revised date: Jan 23, 2018; Accepted date: May 25, 2018

\section{Abstract}

B ACKGROUND: Acute myocardial infarction (AMI) is the most common cause of death in the world. One preventive attempt to reduce AMI is early detection of blood lipid profile. A simple method of lipid profile assessment is the measurement of atherogenic index of plasma (AIP), meanwhile more accurate method of lipid profile assessment is the measurement of apolipoprotein B/apolipoprotien A-I (ApoB/ApoAI) ratio. However, whether both measurements are interchangeable is need to be investigated. This study aims to investigate the correlation between AIP value and ApoB/ApoAI ratio in patients with AMI.

METHODS: The study design was cross-sectional study. The blood samples of consecutively enrolled AMI patients had been selected after inclusion and exclusion criteria. The blood samples were taken within 24 hours of patient admission to the hospital. The blood concentration of high-density lipoprotein (HDL) and triglycerides (TG) were measured using turbidimetric method. The AIP was calculated as logarithmic of TG/HDL ratio ( $\log 10$. [TG:HDL]) The concentration of ApoB and ApoAI were measured using immunoturbidimetric method. The correlation between these measurements was analyzed with Pearson correlation test.

RESULTS: The blood samples of 76 subjects were collected and analyzed. The subjects were dominated by male $(\mathrm{n}=67,88 \%)$ and those whose age $\geq 55$ years old ( $\mathrm{n}=54,71 \%$ ). The mean ApoB value was $88.66 \mathrm{mg} / \mathrm{dL}$ and ApoAI was $97.39 \mathrm{mg} / \mathrm{dL}$. The AIP value was 0.05 . The Pearson correlation test between AIP and ApoB/ApoAI ratio showed a significant positive correlation with the strength of correlation was moderate $(\mathrm{r}=0.51, p$-value $<0.01)$.

CONCLUSION: There was a significantly positive and moderate correlation between AIP value and ApoB/ApoAI ratio in acute myocardial infarction patients.

KEYWORDS: apolipoprotein B/apolipoprotein A-I ratio, atherogenic index of plasma, acute myocardial infarction

Indones Biomed J. 2018; 10(2): 179-83

\section{Introduction}

Ischemic heart disease is the most common cause of death in both men and women worldwide.(1) In Indonesia, ischemic heart disease is on the top seven cause of death or contributes of $5.1 \%$ of crude mortality rate.(2) Acute myocardial infarction (AMI) is the damage of cardiac muscles because of severe or prolonged ischemic.(3) AMI is the result of an atherosclerotic plaque rupture and thrombosis which is blocking the coronary blood vessel that leads to deficiency of blood supply for myocardium.(4)

Heart disease risk can be detected by measurement of lipid level in blood. In 1970, lipoprotein compound was found and considered more specific. The first measurement of low density lipoprotein (LDL) and high density lipoprotein (HDL) cholesterols was done in late 1970.(5) The calculation of lipid level in blood is commonly done 
in the laboratory setting by calculating total cholesterol and triglycerides (TG).(6) Various indices (total cholesterol/ HDL, LDL/HDL and HDL/LDL) are used as the reference value of heart disease risk. In 2000, Dobiasova and Frohlich introduced an index called the atherogenic index of plasma (AIP). In the calculations, AIP also counts TG, so it has a better predictive value in determining cardiovascular risk factors than other indices.(7)

Lee and Alaupovic are the first researchers who stated that lipoprotein can be differentiated into smaller protein particle called apolipoprotein.(8) A case control study by Kwiterovich, et al., showed that apolipoprotein ratio, specifically Apolipoprotein B/Apolipoprotein A-I (ApoB/ApoAI) ratio could be used as risk factor determinant for coronary artery disease (CAD) patients.(9) According to Kaneva, et al., ApoB/ApoAI ratio is the most superior plasma atherogenicity marker.(10) However, the measurement $\mathrm{ApoB} / \mathrm{ApoAI}$ is more difficult and expensive than AIP. The latter is rely on the routine examination of lipid profile ubiquitously used in every hospital laboratory. Dabiasova had classified AIP value into three categories for cardiovascular risk, i.e., low risk $((-0.3)-0.1)$, intermediate risk $(0.1-0.24)$ and high risk $(>0.24)$.(11) Based on the ApoB/ApoA-I ratio, there is also risk classification for cardiovascular events, with value $>0.90$ for males and $>0.80$ for females as high risk. $(12,13)$ This study aims to investigate the correlation between ApoB/ApoAI ratio and AIP value in patients with AMI.

\section{Methods}

This research was designed as cross-sectional study, and was approved by Ministry of Education and Culture Faculty of Medicine Gadjah Mada University Medical and Health Research Ethics Comittee (MHREC), No: KE/FK/817/EC. The data of this current research was extracted from the main research case report form, already published elsewhere. $(14,15)$

The selected subjects were AMI patients treated in Intensive Cardiac Care Unit (ICCU) of Dr. Sardjito General Hospital, Yogyakarta, Indonesia and fulfilled the research criteria. Inclusion criteria of this research were: 1) patients diagnosed with AMI based on two of three criteria i.e., clinically: angina specific chest pain, electrocardiography: elevation of ST or depression of ST or T inverted, and laboratory: increasing of troponin I cardiac enzyme and/ or creatine kinase-MB (CK-MB); 2) patients with the chest pain onset not more than 72 hours; 3 ) patients with age 1875 years; and 4) patients with ability to give an informed consent to participate in the research voluntarily. The exclusion criteria of this research were: 1) patients with stage $\mathrm{V}$ chronic kidney disease, chronic heart failure with The New York Heart Association (NYHA) functional class $\geq$ II, heart valve disease and hepatic cirrhosis; 2) patients with acute comorbidity, i.e., acute stroke, acute infection, sepsis, chronic inflammation disease, diabetes mellitus and vena thromboembolic; and 3) patients with malignancy.

Research subjects were enrolled with consecutive methods. The subjects' demographic data (age, sex, smoking history, hypertension disease history, diabetes mellitus, previous heart disease, and lipid abnormality), clinical data (systole and diastole blood pressure and heart rate frequency), and laboratory data (lipid profile examination such as total cholesterol, TG, HDL, LDL, ApoB, and ApoA-I) were recorded. Blood samples were withdrawn within 24-hour admission in the ICCU under fasting condition. Lipid examination was done to determine the total cholesterol, TG, LDL cholesterol, and HDL cholesterol using turbidimetric method in hospital laboratory. The measurement of $\mathrm{ApoB}$ and ApoAI was performed with Hitachi 902 automated imunoturbidimetric method (Diamond Diagnostic, Holliston, USA).

For statistics analysis, the normality test was done to find data distribution pattern (the Kolmogorov Smirnov test). Based on data distribution pattern the correlation test was performed with Pearson correlation test. The $p$-value of 0.05 was set as a significant limit.

\section{Results}

The number of subjects analyzed were 76 patients. Table 1 shows the characteristic of subjects. The AMI patients were dominated by male (88\%), and most of subjects' age was $\geq 55$ years old ( $71 \%$ ). The most dominant diagnose was myocardial infarct with ST-segment elevation (STEMI) which comprised of $71 \%$ subjects. Most of patients had background as active smokers (53\%) and hypertension $(72 \%)$.

The mean $\mathrm{ApoB}$ value was $88.66 \mathrm{mg} / \mathrm{dL}$ and mean ApoA-I was 97.39. Overall results showed that mean value of $A p o B / A p o A I$ ratio was 0.92 . According to risk classification, the value of $\mathrm{ApoB} / \mathrm{ApoAI}$ ratio was in high risk classification. The mean AIP value was 0.05 , which was low risk according to risk stratification based on AIP. The finding of low AIP value was resulted from normal HDL value and low TG which caused the low ratio of TG/ HDL. Table 2 shows the mean value of apolipoprotein, lipid profile, ApoB/ApoAI ratio and AIP. 
Table 1. The subjects demography characteristics $(n=76)$.

\begin{tabular}{llc}
\hline \multicolumn{1}{c}{ Characteristic } & Frequencies, n (\%) \\
\hline Sex & Males & $67(88.20 \%)$ \\
& Females & $9(11.80 \%)$ \\
\hline Age & $<55$ years & $22(28.90 \%)$ \\
& $\geq 55$ years & $54(71.10 \%)$ \\
\hline AMI Diagnostic & STEMI & $54(71.10 \%)$ \\
& NSTEMI & $22(28.90 \%)$ \\
\hline Smoking status & Never smoke & $20(26.30 \%)$ \\
& Ex-smokers & $15(19.70 \%)$ \\
& Smokers & $41(53.90 \%)$ \\
\hline Hypertension & Yes & $55(72.40 \%)$ \\
& No & $21(21.60 \%)$ \\
\hline
\end{tabular}

AMI: Acute Myocardial Infarction; STEMI: ST-elevation Myocardial Infarction; NSTEMI: Non ST-Elevation Myocardial Infarction

The ApoB/ApoAI ratio was significantly correlated with lipid profile parameters, i.e., total cholesterol $(\mathrm{r}=0.57$, $p$-value $<0.01), \mathrm{TG}(\mathrm{r}=0.40, p$-value $<0.01), \mathrm{HDL}$ cholesterol $(\mathrm{r}=-0.40, p$-value $<0.01)$ and LDL cholesterol $(\mathrm{r}=0.63$, $p$-value $<0.01)$. For the AIP, the correlation was significant with ApoB $(\mathrm{r}=0.35, p$-value $<0.01)$ and LDL cholesterol $(\mathrm{r}=0.24, p$-value $<0.01)$. Table 3 shows the correlation among apolipoprotein and lipid profile with $\mathrm{ApoB} / \mathrm{ApoAI}$ ratio and AIP.

The ApoB/ApoAI ratio had moderate positive and significant correlation with AIP value. The $r$ value was 0.51 with $p$-value $<0.01$. The Figure 1 shows the scatter plot of the correlation between AIP value and ApoB/ApoAI ratio.

\section{Discussion}

In this study, there was a significantly positive and moderate correlation between AIP value and ApoB/ApoAI ratio. Among subjects with AMI, AIP value did not indicate the high risk classification for cardiovascular event. In contrast, the ApoB/ApoAI ratio indicated high risk for cardiovascular disease. Indeed, the subjects were those who had undergone cardiovascular event, i.e., AMI. The gender, male and female, did not affect this high risk classification based on the ApoB/ApoAI ratio.

AMI is a clinical syndrome caused by coronary artery occlusion. In result of that occlusion, the decrease of oxygen flow to cardiac muscle cell (ischemia) induces a muscle cell death (necrosis) in the supplied area.(16) Muscle cell necrosis is influenced by the time of coronary artery occlusion.(17) According to Willerson, et al., AMI occurs at minimum 20 minutes after cardiac muscle cell does not receive oxygen supply.(3)

Atherosclerotic in coronary artery is the most important part of AMI disease development. It is initiated with LDL deposition in intimal layer of coronary artery and formation a fibrous cap lesion that can easily rupture. Once ruptured, it promotes the development of intracoronary thrombosis. (16) When thrombosis spread and block the arterial blood flow, it will cause cardiac muscle ischemia in distal area of obstruction. If the event happens in a severe and long time, it can induce cardiac muscle necrosis or infarct. (16)

AIP is a logarithm of TG ratio and HDL $(\log 10$ TG/HDL). Both have molar unit. Research analysis of

Table 2. The mean value of apoliprotein and lipid profile among subjects.

\begin{tabular}{|c|c|c|c|c|c|c|}
\hline \multirow{2}{*}{ Variables } & \multirow{2}{*}{ Mean } & \multirow{2}{*}{$\begin{array}{c}\text { Minimum } \\
\text { Value }\end{array}$} & \multirow{2}{*}{$\begin{array}{c}\text { Maximum } \\
\text { Value }\end{array}$} & \multicolumn{2}{|c|}{ Mean } & \multirow{2}{*}{$p$-value* } \\
\hline & & & & Males & Females & \\
\hline $\operatorname{ApoB}(\mathrm{mg} / \mathrm{dL})$ & 88.66 & 32.90 & 149.00 & 88.43 & 90.34 & 0.89 \\
\hline ApoAI (mg/dL) & 97.39 & 55.00 & 130.00 & 96.79 & 101.89 & 0.39 \\
\hline Total Cholesterol (mg/dL) & 176.78 & 86.00 & 273.00 & 175.34 & 187.56 & 0.37 \\
\hline Triglyceride $(\mathrm{mmol} / \mathrm{L})$ & 1.24 & 0.54 & 2.34 & 1.24 & 1.27 & 0.81 \\
\hline $\mathrm{HDL}(\mathrm{mmol} / \mathrm{L})$ & 1.07 & 0.49 & 1.68 & 1.05 & 1.21 & 0.06 \\
\hline $\mathrm{LDL}(\mathrm{mmol} / \mathrm{L})$ & 3.04 & 1.11 & 5.21 & 3.02 & 3.22 & 0.53 \\
\hline LDL/HDL & 2.95 & 1.14 & 4.90 & 2.98 & 2.77 & 0.55 \\
\hline ApoB/ApoAI & 0.92 & 0.46 & 1.37 & 0.93 & 0.86 & 0.48 \\
\hline AIP & 0.05 & -0.38 & 0.42 & 0.06 & 0.00 & 0.44 \\
\hline
\end{tabular}

ApoB : Apolipoprotein-B, ApoAI : Apolipoprotein A-I, HDL : High Density Lipoprotein, LDL : Low Density Lipoprotein, AIP : Atherogenic Index of Plasma. * $p$-value for comparison between males and females, tested with independent Student T-test. 
Table 3. The correlation among apolipoprotein and lipid profile with ApoB/ApoAI ratio and AIP.

\begin{tabular}{lcccc}
\hline \multirow{2}{*}{ Variables } & \multicolumn{2}{c}{ ApoB/ ApoAI } & \multicolumn{2}{c}{ AIP } \\
\cline { 2 - 5 } & rvalue & $\boldsymbol{p}$-value* & r value & $\boldsymbol{p}$-value* \\
\hline ApoB & 0.78 & $<0.01$ & 0.35 & $<0.01$ \\
ApoA-I & -0.22 & N.S & -0.19 & N.S \\
Total Cholesterol & 0.57 & $<0.01$ & 0.16 & N.S \\
Triglyceride & 0.40 & $<0.01$ & 0.84 & $<0.01$ \\
HDL & -0.40 & $<0.01$ & -0.70 & $<0.01$ \\
LDL & 0.63 & $<0.01$ & 0.24 & $<0.01$ \\
\hline
\end{tabular}

ApoB : Apolipoprotein-B; ApoAI : Apolipoprotein A-I; HDL : High Density Lipoprotein; LDL: Low Density Lipoprotein; AIP: Atherogenic Index of Plasma. *tested with Pearson correlation test.

Dobiasova and Frohlich in 1156 subjects, showed that AIP was recommended as the most sensitive index to determine profile of plasma atherogenicity as risk factor of heart disease.(7) In another study, AIP proved to have higher sensitivity (84\%) than other indexes such as total cholesterol/HDL (68\%), HDL/LDL (73\%), LDL/HDL (76\%). Specificity of AIP is $99 \%$, equivalent with other indexes.(18) In the group without the risk (children, healthy females, etc.), AIP value is 0 or negative. In the group with the risk (males and menopause females), and group with high risk (diabetic patients, hyperkeratosis lenticularis perstans (HLP) patients, patients with positive angiography and AMI) AIP increased to positive value.(7) Our study shows that the subjects had low risk classification for

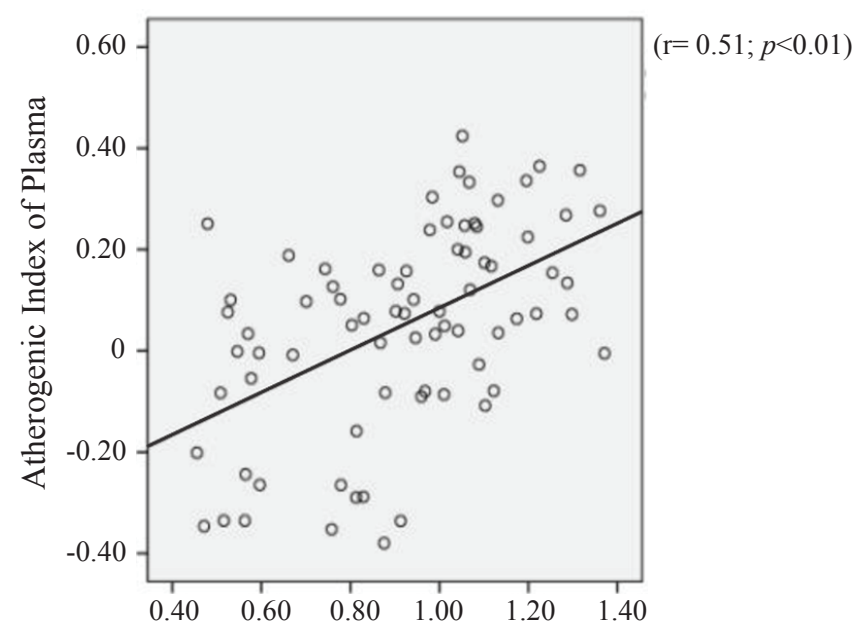

Apolipoprotein B/Apolipoprotein A-I Ratio

Figure 1. The scatter plot of correlation between ApoB/ApoAI ratio and $A I P$ value. cardiovascular event based on AIP value. However based on ApoB/ApoAI ratio, subjects had high risk classification for cardiovascular event.

In study conducted by McQueen, et al., it was concluded that ApoB/ApoAI ratio in patients who did not fast, was more superior than other cholesterol indexes in determine the AMI risk in all range of age, sex, and ethnics.(19) Other study by Kaneva, et al., showed that ratio of ApoB/ApoAI value was the most superior marker for determining plasma atherogenicity rather than traditional lipid marker and new few markers such as ApoE and AIP.(10)

The mean value of AIP in this study classified as low risk, different with the mean ApoB/ApoAI ratio which classified as high risk. However, both were sufficiently correlated. The AIP value can not represent ApoB/ApoAI ratio. Further research will be needed to assess compatibility of risk categories and interaction of both indexes, including influence of risk factors (age, sex, lipoprotein level, and TG level) towards AIP and ApoB/ ApoAI ratio. This is corresponding with study by Kaneva, et al., which showed positive correlation between AIP and ApoB/ApoAI ratio.(10) However, overall AIP value can not represent ApoB/ApoAI ratio. According to Kaneva, et al., AIP only represented qualitative lipoprotein composition, whereas $\mathrm{ApoB} / \mathrm{ApoAI}$ ratio showed quantitative lipoprotein composition. (10)

The limitation of this study were: 1) there was no control of dyslipidemia drugs consumption; 2) history of subjects' previous lipid profiles were unknown; and 3) the number of females subjects was unbalanced with males. Further research will be needed to corroborate our finding. 


\section{Conclusion}

The conclusion of this study is there is a significantly positive and moderate correlation between the ApoB/ApoA-I ratio with AIP in patients with acute myocardial infarction.

\section{Acknowledgment}

The authors were grateful to dr. Catherine Halim and dr. Ira Puspitawati, Sp.PK(K), from Department of Clinical Pathology Faculty of Medicine Universitas Gadjah MadaDr. Sardjito Hospital, Yogyakarta, Indonesia. Also, we were thankful to medical and paramedical staffs in emergency room and ICCU of Dr. Sardjito Hospital, Yogyakarta, Indonesia.

This research was funded by Dana Masyarakat Faculty of Medicine Universitas Gadjah Mada, Yogyakarta, Indonesia fiscal year 2013 to Anggoro Budi Hartopo, MD, $\mathrm{PhD}$, as the Principal Investigator.

\section{References}

1. World Health Organization [Internet]. Cardiovascular diseases (CVDs) [cited 2015 Apr 27]. Available from: http://www.who.int/ mediacentre/factsheets/fs317/en/.

2. Badan Penelitian dan Pengembangan Kesehatan Kementrian Kesehatan Republik Indonesia. Riset Kesehatan Dasar (RISKESDAS) Tahun 2007. Jakarta: Kementrian Kesehatan RI; 2007.

3. Willerson JT, Cohn JN, Wellens HJJ, Holmes DR Jr. Cardiovascular Medicine. 3rd ed. London: Springer; 2007.

4. Faqih DM, Paranadipa M, Trisna DV, Waluyo DA, Herqutanto, Ekayanti F, et al. Panduan Praktik Klinis Bagi Dokter di Fasilitas Pelayanan Kesehatan Primer. 1st edition. Jakarta: Ikatan Dokter Indonesia; 2013.

5. Expert Panel on Detection, Evaluation, and Treatment of High Blood Cholesterol in Adults. Executive summary of the third report of the national cholesterol education program (NCEP) expert panel on detection, evaluation, and treatment of high blood cholesterol in adults (Adult Treatment Panel III). JAMA. 2001; 285: 2486-97.
6. Baynes JW, Dominiczak MH. Medical Biochemistry. 2nd edition. London: Elsevier; 2007.

7. Dobiasova M, Frohlich J. The new atherogenic plasma index reflects the triglyceride andHDL-cholesterol ratio, the lipoprotein particle size and the cholesterolesterification rate: changes during lipanor therapy. Vnitr Lek. 2000; 46: 152-56.

8. Lee DM, Alaupovic P. Composition and concentration of apolipoproteins in very-low- and low-density lipoproteins of normal human plasma. Atherosclerosis. 1974; 19: 501-20.

9. Kwiterovich PO Jr, Coresh J, Smith HH, Bachorik PS, Derby CA, Pearson TA. Comparison of the plasma levels of apolipoproteins B and A-1, and other risk factors in men and women with premature coronary artery disease. Am J Cardiol. 1992; 69: 1015-21.

10. Kaneva AM, Potolitsyna NN, Bojko ER, Odland JØ. The apolipoprotein B/apolipoprotein A-I ratio as a potential marker of plasma atherogenicity. Dis Markers. 2015; 2015: 591454. doi: 10.1155/2015/591454.

11. Dobiasova M. AIP--Atherogenic index of plasma as a significant predictor of cardiovascular risk: from research to practice. Vnitr Lek. 2006; 52: 64-71.

12. Walldius G, Jungner I, Holme I, Aastveit AH, Kolar W, Steiner E. High apolipoprotein B, low apolipoprotein A-I, and improvement in the prediction of fatal myocardial infarction (AMORIS Study): a prospective study. Lancet. 2001; 358: 2026-33.

13. Yusuf S, Hawken S, Ounpuu S, Dans T, Avezum A, Lanas F, et al. Effect of potentially modifiable risk factors associated with myocardial infarction in 52 countries (the INTERHEART study): case-control study. Lancet. 2004; 364: 937-52.

14. Hartopo AB, Gharini PPR, Hariawan H, Puspitawati I. Lipid Terogenik Plasma Sebagai Prediktor Kejadian Buruk Kardiovaskular Selama Perawatan Penderita Sindroma Koroner Akut [Laporan Penelitian]. Yogyakarta: Fakultas Kedokteran Universitas Gadjah Mada; 2013.

15. Saputri D, Hariawan H, Irawan B. High Apo B/Apo A-1 serum ratio as a predictor of in-hospital major adverse cardiovascular events in acute coronary syndrome patients. Acta Cardiol Indones. 2015; 1: $52-9$.

16. Crawford MH. Current Diagnosis \& Treatment: Cardiology. 3rd ed. USA: McGraw-Hill Companiesl; 2009.

17. Fuster V, Walsh RA, O'Rourke RA, Poole-Wilson P. Hurst's the Heart. 13th ed. USA: McGraw-Hill Companies; 2011.

18. Khazaal MS. Atherogenic index of plasma (AIP) as a parameter in predicting cardiovascular risk in males compared to the conventional dyslipidemic indices (cholesterol ratios). Karbala J Med. 2013; 6: 1506-13.

19. McQueen MJ, Hawken S, Wang X, Ounpuu S, Sniderman A, Probstfield $\mathrm{J}$, et al. Lipids, lipoproteins, and apolipoproteins as risk markers of myocardial infarction in 52 countries (the INTERHEARTstudy): a case-control study. Lancet. 2008; 72: 22433 . 